\title{
CHARLES CHREE AND HIS WORK ON GEOMAGNETISM*
}

\author{
By Prof. S. Chapman, F.R.S.
}

$\mathrm{C}^{\mathrm{H}}$ ARLES CHREE, a son of the manse, an Aberdonian scholar brilliant in classics as well as in science, distinguished later at Cambridge as a mathematical expert on the theory of elasticity, in 1893 took up new and very different labours as superintendent of the magnetic and meteorological observatory at Kew. When he retired in 1925 he was president of both the international organizations concerned with geomagnetism.

\section{British Contributions to Geomagnetism}

In the earth sciences, most of all, international co-operation is a necessity for progress ; yet each nation may feel pride in its own contributions to the common stock. In gəomagnetism Britain has a long and distinguished record. Queen Elizabeth's hydrographer Robert Norman was the first to maasure the magnetic dip (1576) ; her physician William Gilbert wrote "de Magnete" (1600), the first modern scientific treatise. Gellibrand, Gresham professor, discovered the secular magnetic variation (1634); Halley made.the first scientific voyages (1698-1700) to measure the magnetic declination, and also constructed the first magnetic chart (1701). Graham, the London instrument maker, discovered the transient magnetic variations (1724).

In the nineteenth century Sabine fostered the British Colonial magnetic observatories, discovered the 11-year cycle in geomagnetism, and like Broun of Trevandrum, made notable studies of the lunar geomagnetic tide. Balfour Stewart was the first to realize the existence of the ionosphere as the primary source, through dynamo action, of the daily magnetic variations (1882). Schuster applied Gauss's method of spherical harmonic analysis to these variations (1889), and developed Stewart's dynamo theory (1908). Maunder made brilliant studies on the connexions between the sun and magnetic storms (1904-16).

\section{Chree and his Contemporaries}

Chree, contemporary with Schuster and Maunder, was in this distinguished succession, and his name will endure in the history of geomagnetism. Other notable contemporaries were Bauer, the initiator and first director of the Department of Terrestrial Magnetism of the Carnegie Institution of Washington, and Schmidt, van Bemmelen and Moos,

* From the first Charles Chree Address to the Physical Society, delivered on July 25 . The latter part of the address, referring to the future of world magnetic surveying, is not included in this summary. the directors of the magnetic observatories at Potsdam, Batavia and Bombay; like Chree, they were not content with maintaining a high standard of accuracy in the magnetic measurements under their charge; they had also the energy, ability and inward impulse to undertake the scientific discussion of their records.

Chree maintained the reputation of Kew as a magnetic centre of the first rank; he standardized magnetic instruments, trained many young men to use them, notably on polar and other magnetic expeditions, and gave immense time and effort to the discussion not only of the Kew data, but also of records obtained by four Antarctic expeditions. He brought to his work, besides untiring industry and devotion, a meticulous attention to detail, and a clear, critical and scrupulously exact mind.

Geomagnetism has need of men of widely different gifts : of the organizer and administrator ; of the man of affairs, who can influence Governments or private benefactors to provide resources for the science; of the navigator and explorer; of the instrument designer and maker; of the patient, skilled and resourceful observer, often far from social and technical centres; of the faithful computer, zealous for detailed accuracy; of the investigator, theorist and writer.

Bauer was a man of enthusiasm and energy, who took wide views and realized great projects ; but his eagerness to reach conclusions, where sometimes judgment was better deferred, met a useful corrective in Chree's critical detachment, which later administered some cooling draughts to my own youthful optimism. Schuster, though perhaps not Chree's equal as a mathematician, nor with a tithe of his detailed knowledge of geomagnetism, could make brilliant sorties into the subject, leading to striking theoretical conclusions ; by labours trifling compared with Chree's, he lifted some parts of the subject to a new level. Maunder had a daily familiarity with the sun's aspect, as well as with the Greenwich magnetic records; this enabled him to perceive certain remarkable associations between the sun and magnetic storms; his work stimulated Chree to sorne of his finest achievements.

Whereas Schuster, Maunder and Bauer were ready to make hypotheses, Chree held that a theory was not necessary as a guide to research, and he refrained from speculation; nevertheless his work was greatly influenced by the speculations of Maunder and Arrhenius on the magnetic effects of streams of particles emitted from the sun. 


\section{Does Geomagnetic Disturbance Lag Behind SOLAR ACTIVITY?}

Chree showed that when there were many or large spots on the sun, days of geomagnetic calm were rarer than on days of no or few spots ; but the difference was very slight. He concluded that geomagnetic disturbance could not depend directly in any large degree on the simultaneous area of spots on the sun, but that his results might easily be reconciled with Arrhenius's view that geomagnetic disturbance lagged two or three days after the solar cause, because of the time taken by the solar particles to travel from the sun to the earth.

To study this possibility, Chree in 1908 devised a new method of great value and power, which $\mathrm{I}$ have called the method of superposed epochs. $\mathrm{He}$ examined how, on the average, the sunspot area varied during a number of intervals, each of 4 days, and each ending with a day of selected geomagnetic character (either calm or disturbed): thus in the averaging, the epochs of these selected days were superposed. Later he and his followers considered intervals of greater length, extending after as well as before the selected superposed days; he

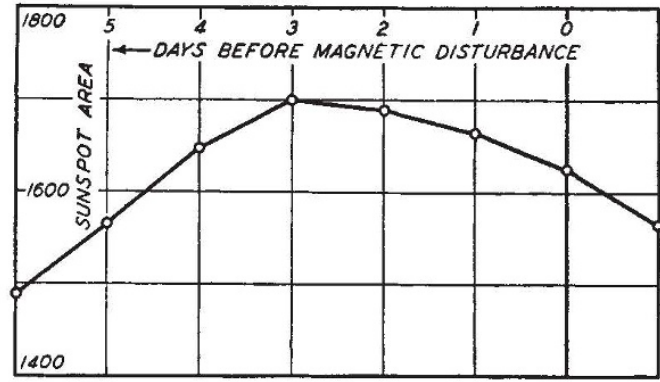

YEARS WITH MANY SUNSPOTS

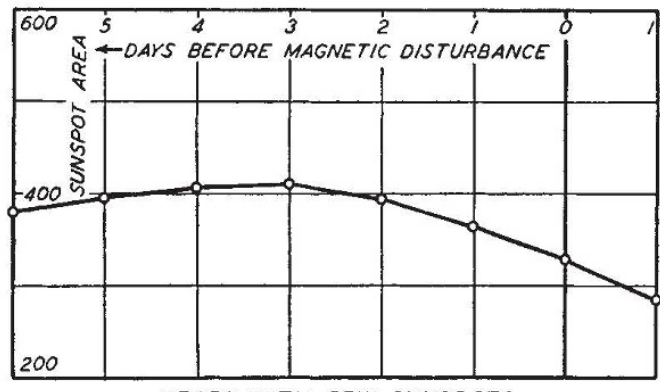

YEARS WITH FEW SUNSPOTS

Fig. 1*.

Average sUNSPOT AREAS, EXPRESSED IN MILLIONTHS OF THE SUN'S DISK, FROM 6 DAXS BEFORE UNTIL 1 DAY AFTER DAYS (EPOCH 0) SECECTED AS MAGNETICAILY DISTURBED.

Above : averages for 250 sets of days in years with many sunspots. Below : averages for 116 sets of days in years with few sunspots. After J. M. Stagg.

* This, and the other illustrations, are from "Geomagnetism", by Prof. S. Chapman and Dr. J. Bartels (Oxford University Press, 1940).

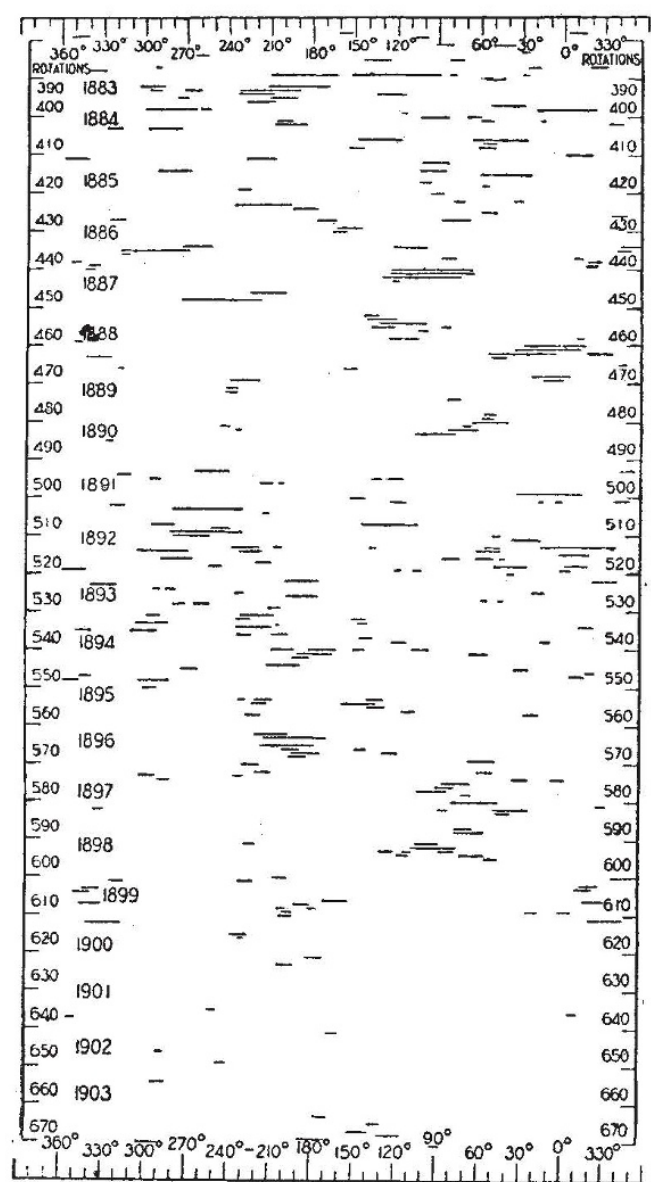

Fig. 2 .

Distribution OF MAGNETIC - DISTURBANCES, 1882 1903, ACCORDING TO THE HELIOGRAPHIC LONGITUDE OF THE CENTRE OF THE SUN'S DISK AT THE TIME OF thetr Commencement. After E. W. Maunder.

also considered in the same way the average variation of the geomagnetic activity before and after days of selected sunspot character.

In the hands of Maurain, and later of Stagg, using much more material than Chree, results were thus obtained which leave little room for doubt that on the average, on days of notable geomagnetic disturbance, the sunspottedness is declining from a maximum value attained two or three days earlier (Fig. 1); but the sunspot peak is shallow, and may be obscured by accidental circumstances if the material is too scanty to average these out. This is the less surprising because sunspots are at least not the sole cause of magnetic disturbance, which sometimes occurs during intervals of many days free from sunspots.

\section{The 27-Day Recurrence Tendency}

Chree's method was thus successful in elucidating an important interrelationship between solar and geomagnetic data. Chree also made a still more 
beautiful and successful application of his method, to test a time relationship appearing in the geomagnetic data by themselves. This is a tendency for geomagnetic conditions of exceptional calm or exceptional disturbance to recur, generally with diminished intensity, after about 27 days; it is therefore called the 27-day recurrence tendency.

This had been recognized by Broun (1858) and by many others after him, who had directed attention to a 'period' of 27 or 28 days in magnetic and auroral phenomena. But its nature was not understood, and even its existence was often doubted or overlooked, until Maunder rediscovered it and demonstrated its real character in 1904. Some of his predecessors had thought it might be connected with the lunar month; but Maunder, deeply imbued with a knowledge of the succession of both solar and magnetic phenomena, was quite clear as to its solar origin. He regarded the sun as intermittently ejecting limited streams of corpuscles which, like water from a fire-hose, may sweep the earth at successive rotations of the sun, if the emission is sufficiently prolonged. His presentation of his discovery was made with this idea in view, and from the point of view of the solar physicist.

His demonstration was graphical, by means of a diagram (Fig. 2) in which the solar longitude of the centre of the sun's disk (as viewed from the earth) is measured along a succession of horizontal lines drawn at equal vertical intervals; each line represents one rotation, occupying $27 \cdot 3$ days, of a certain standard meridian on the sun. If during any such rotation one or more geomagnetic storms occurred, Maunder marked the part or parts of the horizontal line for that rotation, between the solar longitudes corresponding to the beginning and end of the storm ; the remaining part of this and other lines, not corresponding to the occurrence of a storm, was obliterated (or rather not drawn). The diagram shows that many of these storm lines fall nearly on the same vertical, corresponding to nearly the same solar longitude, and indicating a recurrence after an interval of one or more solar rotation periods of $27 \cdot 3$ days.

Maunder's diagram, however, has no necessary connexion with the sun; it forms what I have called a time-pattern, in which successive horizontal lines represent merely successive intervals of $27 \cdot 3$ days. Maunder adopted the $27 \cdot 3$ day interval because it is the mean rotation period of sunspots ; but he recognized that if a sequence of storms occurred at a slightly different interval, this would be clearly shown by a slight displacement of their successive 'lines' to the right or to the left. In his diagram the sequences of storm lines are rarely so clear cut as to show whether the usual interval is $27 \cdot 3$ days, or half a day more or less than this.
The identification of the mean recurrence interval with the solar rotation period is an independent step which, though highly probable, is a speculation rather than, like the recurrence interval itself, an established fact.

\section{Chree's 27-Day Pulse Diagram}

Chree applied his superposed epoch method to this question, using as the selected epochs days of

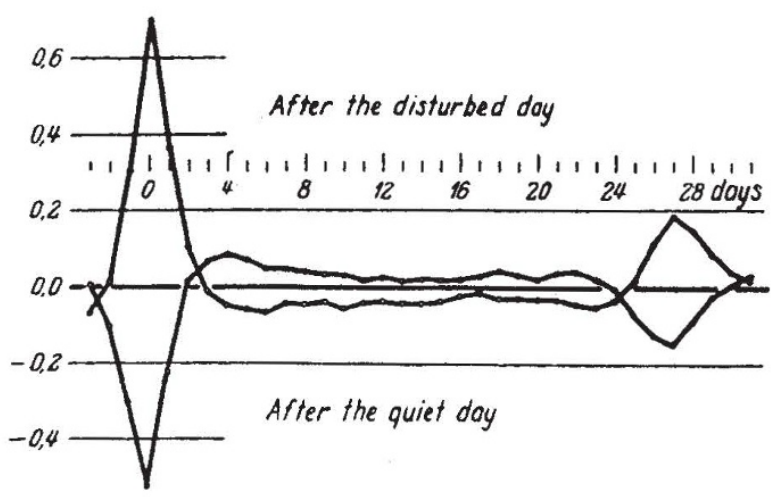

Fig. $3 a$.

AVERAGE CHANGE IN THE DATLY MAGNETIC CHARACTERFIGURES, INDICATED BY THE DEVIATIONS FROM THE MEAN, FROM FOUR DAYS BEFORE UNTIL 31 DAYS AFTER A SET OF DISTURBED OR A SET OF QUIET DAYS, 1906-24. After Chree and Stagg.

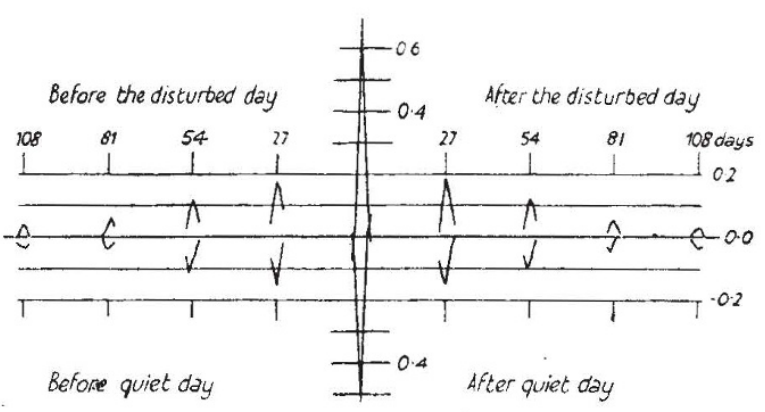

Fig. $3 b$.

AVERAGE CHANGE IN THE DAILY MAGNETIC CHARACTERFIGURES, INDICATED BY THE DEVIATIONS FROM THE MEAN, FOR GROUPS OF DAYS AROUND A SET OF DISTURBED OR A SET OF QUIET DAYS (CENTRE), AND AROUND EPOCHS I, 2, 3, 4 SOLAR ROTATIONS (OF 27 DAYS EACH) BEFORE AND AFTER. After Chree and Stagg.

either disturbed or quiet geomagnetic conditions. The daily data averaged for these days, and for the preceding and following days, were purely magnetic, namely the character figures internationally assigned as an index of each Greenwich day's geomagnetic activity. Some of his results are illustrated in Fig. $3(a, b)$; the upper and lower parts of Fig. $3 a$ refer respectively to the averages when the selected epochs are disturbed or calm. There are naturally peaks (positive or negative) for the selected days; there are also peaks 27 days 
afterwards. This demonstrates the recurrence tendency and gives an indication of the recurrence interval, while involving absolutely no preconceived notion as to its length or significance.

Later Chree showed that there are corresponding peaks, of diminishing height (or depth) at about 54 and 81 days after the selected disturbed (or quiet) days, and also at similar intervals before them (Fig. 3b, where the averages for the days not near the peaks are not shown).

In my opinion this beautiful and brilliant application of his method is Chree's highest achievement and best gift to geomagnetic science ; his fame will always be linked with his pulse diagrams. This

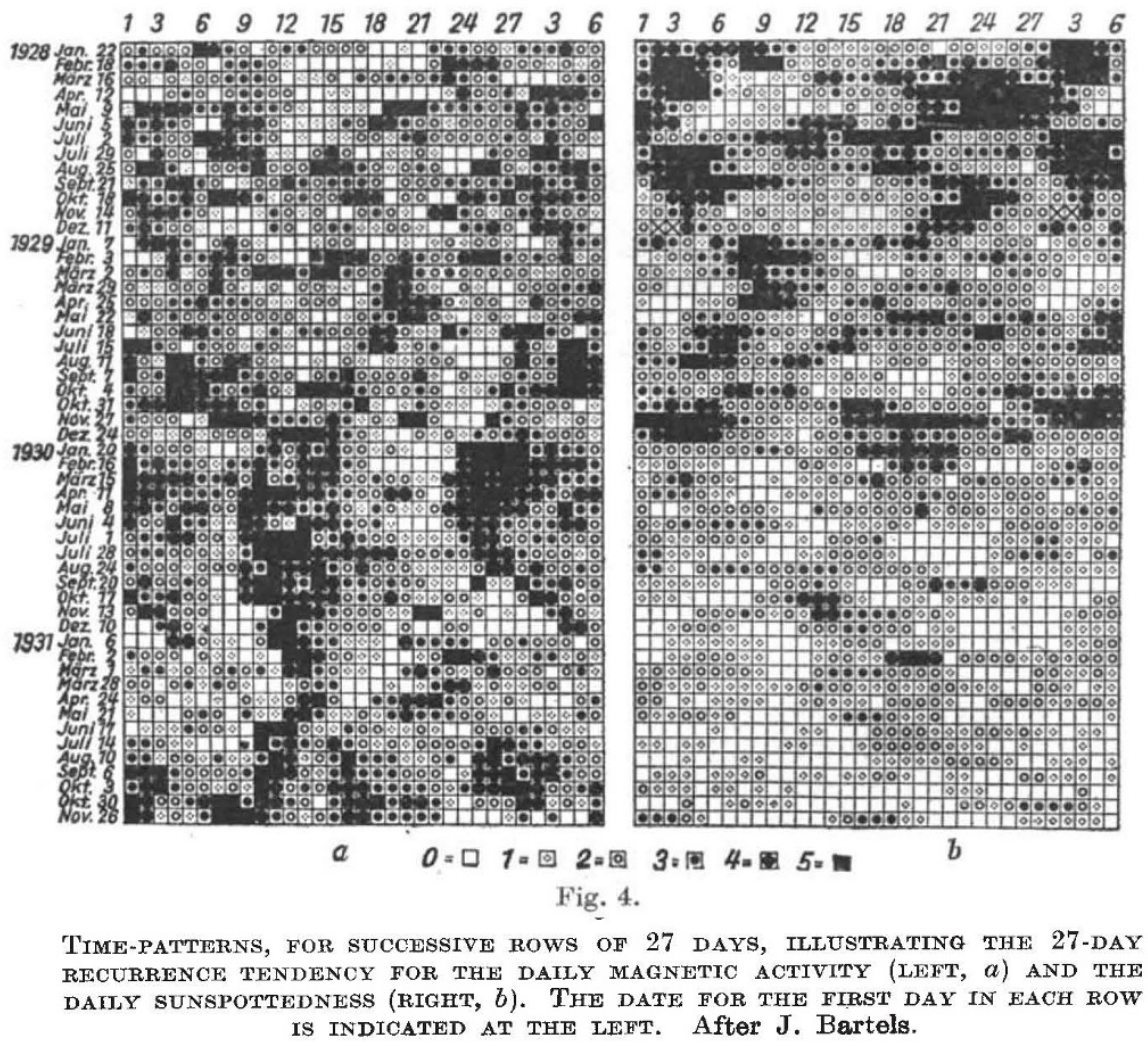

TIME-PATTERNS, FOR SUCCESSIVE ROWS OF 27 DAYS, ILLUSTRATING THE 27-DAY RECURRENCE TENDENCY FOR THE DAILY MAGNETIC ACTIVITY (LEFT, $a$ ) AND THE DAILY SUNSPOTTEDNESS (RIGHT, $b$ ). THE DATE FOR THE FIRST DAY IN EACH ROW IS INDICATED AT THE LEFT. After J. Bartels.

graphic product of his genius fitly·finds a place on the Chree Medal.

Within the last two years Chree's method of superposed epochs has found useful applications to the time relationships of cosmic ray data, both as regards interrelationships with geomagnetic activity, and as regards the 27-day recurrence tendency in cosmic ray measures alone.

\section{TIME-PATTERNS}

Chree examined in great detail the significance of the recurrence pulses in his diagrams, to see, for example, whether they were due to the recurrence of a few notable days of the selected character, or merely to the occurrence of that character to a more moderate degree in a large proportion of days around the recurrence epoch.

In the course of such detailed investigation undertaken by Chree later, in conjunction with Stagg, differences were found between the pulse recurrences in 1920-21 and 1922-23. To examine these in more detail, they constructed two 27-day time-patterns, on which the international daily magnetic character figures were arranged in successive 27-day rows; these figures were entered only for specially quiet or specially disturbed days, so that most of the 'pattern' was blank (as in Fig. 2); it showed the recurrence tendency in the

same manner as in Fig. 2, by the grouping of disturbed or quiet days along the same verticals.

This diagram by Chree and Stagg forms a transitional stage between Maunder's diagram and later time-patterns constructed by Bartels. Maunder's diagram, despite its solar 'dress', was a true timepattern, each row representing $27 \cdot 3$ days; it showed the occurrence of outstanding megnetic disturbance, beginning and ending at different Greenwich times, and of varying duration; the greater portion of the diagram was empty. The Chree-Stagg time-pattern was also mainly empty ; it showed specially quiet as well as specially disturbed periods; but these were taken in units of the Greenwich day, and the horizontal range of 
the diagram is 27 days (this does not prevent the diagram from showing a recurrence interval differing from 27 days; recurrences with a different interval would be shown by a slope of the sequences in successive rows).

Bartels by successive stages brought the 27-day time-pattern to perfection (1) by including all days, and (2) by indicating their magnetic character by a greater or less proportion of black (representing magnetic activity) in the square corresponding to each day. The result is shown in Fig. 4 (left); such a diagram represents an extraordinary concentration of knowledge, derived from magnetic observatories all over the world, over a period of nearly four years. The recurrence tendency is clearly shown by the 'columnar' distribution of the blackest and lightest parts of the diagram, though at least one recurrence sequence (near the end of
1930) is notably sloping, implying a recurrence interval of more than 28 days.

Bartels also applied his method to construct a time-pattern of solar activity, based on the daily sunspot number, as shown in Fig. 4 (right). The comparative study of the two diagrams for the same period is of great interest. The decline from the maximum (1928) of the sunspot cycle is much more strongly manifested by sunspots than by magnetic disturbance, and even in periods when both the sun and magnetic disturbance were active, their timepatterns are often very different. This shows that sunspots are often not a good index of the agencies on the sun that cause geomagnetic disturbance.

I feel confident that not only the method of superposed epochs, but also the study of timepatterns, has much still to contribute to geophysics and cosmical physics.

\section{THE STUDY OF ENERGY-LEVELS IN BIOCHEMISTRY*}

\section{By Prof. A. Szent-Gyorgyi, UnIVERSity of SZEGED, Hungary}

$\mathrm{T}$ $\mathrm{HE}$ atom consists of a nucleus surrounded by a system of electrons. By sharing one or more electrons, atoms can join to form molecules. In such a molecule, as a rule, every electron belongs to one or two atoms. This is our idea of a single small molecule, and this picture has hitherto unconsciously governed our thinking in biochemistry.

The study of crystals and metals, however, has revealed the existence of a different state of matter. If a great number of atoms be arranged with regularity in close proximity, as for example, in a crystal lattice, the terms of the single valency electrons may fuse into common bands. The electrons in this band cease to belong to one or two atoms only, and belong to the whole system.

These bands or energy-levels are separated from possibly higher levels by forbidden zones. Under ordinary conditions all electrons are within the lowest band. If this lowest band contains the maximum number of electrons ( $2 n$, if the number of atoms is $n$ ), as is the case with insulators, the electrons will be unable to transport energy. If, however, one of these electrons is raised by the absorption of energy to a higher level, and comes to be in what we call an excited state, where it will move and transport its energy freely, it will be impossible to say which is the atom to which

* Substance of the Korányi Memorial Lecture, given in Budapest on March 21, 1941. the excited electron belongs, and the whole system can be looked upon as activated. By falling back to the lower level the electron will give off its excess energy and perform work in a place more or less distant from that of the absorption of energy. This is the case with certain phosphors, as has been shown recently by $\mathrm{N}$. Riehl ${ }^{1}$. Here, as for example in zinc sulphide, the electron, raised to a higher level by a collision with an $\alpha$-particle, can travel relatively long distances and will fall back to a lower level, giving up its energy where it meets a copper atom present as an impurity. Thus the absorption and emission of energy will proceed independently at different places.

The problem is whether this state of matter, that is, common energy-levels, exists also in living systems. If it does, it cannot fail to influence profoundly our biological thinking and open new approaches to research and understanding. Protein molecules are systems built up of a great number of atoms, closely packed with great regularity. So theoretically the possibility exists that within these molecules analogous conditions prevail to those in crystals.

The first indication of the existence of such common energy-levels was given by the study of photosynthesis. Emerson and Arnold ${ }^{2}$ found that 2,500 chlorophyll molecules form one functional unit. Warburg and Negelein ${ }^{3}$ showed that four quanta are necessary for the reduction of one 